\title{
Bazı yaprak psyllidleri (Hemiptera: Psyllidae)' nin mücadelesinde yeni bir feromon preparatının etkisi
}

\author{
Effect of a new pheromone preparation on leaf psyllids (Hemiptera: Psyllidae) \\ control
}

\section{Mert KOSOVAERi ${ }^{1 *}$}

\author{
Hatice KAVAK $^{1}$ Özgür KABAN ${ }^{1}$
}

\section{Oktay DURSUN ${ }^{1}$}

\begin{abstract}
Summary
This study was carried out to understand the effects of a new pheromone formula (CacPyr Attractants for Psyllids) produced by Novagrica (France) against to Cacopsylla pyrii L. and Agonoscena pistaciae Burckhardt \& Lauterer (Hemiptera: Psyllidae) which are the important pests on pear and pistachio. With this aim two different pear gardens in Ula (Muğla: Turkey) and one pistacihio garden in Suruç (Şanlıurfa: Turkey) was selected. Studies were conducted in 2014 from March to July. Pheromone formulation was used with some trap combinations. These combinations were: 1-yellow sticky traps 2- pheremone+yellow sticky traps 3- pheremone + delta traps. Pest populations were counted monthly on the combinations. It was seen that pheremone formulations were not as effective as yellow sticky traps. With the result of this study it is proved that the new pheromone preparation (CacPyr Attractants for Psyllids (Novagrica- France)) don't have hopeful effects to control of Cacopsylla pyri and Agonoscena pistaciae.
\end{abstract}

Key words: Cacopsylla pyri, Agonoscena pistaciae, yellow sticky trap.

\section{Özet}

Bu çalışma Novagrica (Fransa) firması tarafından üretilen yeni bir feromon formulasyonunun (CacPyr Attractants for Psyllids) armut ve antep fıstığının önemli zararlılarından olan Cacopsylla pyri L. ve Agonoscena pistaciae Burckhardt \& Lauterer (Hemiptera: Psyllidae)' ye karşı etkilerinin saptanması amacıyla yürütülmüştür. Bu amaçla Ula (Muğla: Turkiye)'da iki adet armut bahçesi ve Suruç (Şanlıurfa: Turkiye) 'da bir adet fıstık bahçesi seçilmiştir. Çalışmalar 2014 yılı Mart- Haziran ayları arasında yürütülmüştür. Feromon formulasyonu çeşitli tuzaklarla kombinasyon yapılarak kullanıımıştır. Bu kombinasyonlar: 1-sarı yapışkan tuzak 2- feromon+ sarı yapışkan tuzak 3feromon+ delta tuzak' dır. Kombinasyonlar üzerindeki zararlılar aylık olarak sayılıııstır. Yeni feromon formulasyonunun sarı yapışkan tuzak kadar etkili olmadığı görülmüştür. Çalışma sonucunda yeni feromon formulasyonun (CacPyr Attractants for Psyllids (Novagrica- France)) Cacopsylla pyri ve Agonoscena pistaciae ' nin kontrolünde umut verici bir sonuca sahip olmadığı ortaya konulmuştur.

Anahtar sözcükler: Cacopsylla pyri, Agonoscena pistaciae, sarı yapışkan tuzak

\footnotetext{
${ }^{1}$ Muğla Sıtkı Koçman Üniversitesi, Fen Fakültesi, Biyoloji Bölümü, Muğla

* Sorumlu yazar (Corresponding author) e-mail: mert_kosovaeri@hotmail.com

Alınış (Received): 20.10.2014 Kabul ediliş (Accepted): 22.12.2014
} 


\section{Giriş}

Türkiye'nin 2013 yılı toplam tarım alanı 238.055.119,07 dekardır. Bu alanın 6.842,617 dekarı sert çekirdekli ve yumuşak çekirdekli meyve alanlarıdır. Armut yumuşak çekirdekli meyveler içinde olup 461.826 ton üretimi ile elma, kayısı, şeftali ve kirazdan sonra beşinci sırada yer almaktadır. (Anonymous, 2013).

Armut kültürünün en eski yapıldığı ülkeler arasında; Anadolu, İtalya, Fransa ve Belçika yer almaktadır. Armut gerek taze olarak sofralık tüketimi olan gerekse konserveye işlenerek ve kurutularak değerlendirilen ekonomik öneme sahip bir meyvedir. Dünyadaki armut çeşitlerinin sayısının 5000' den fazla ve Türkiye'de yetiştirilenlerin sayısının ise 640 dolayında olduğu tahmin edilmektedir (Soylu, 1997).

Dünyada antepfıstığı üretimi yıllık ortalama 600 bin ton civarındadır. 2006-2009 yılı FAO kaynaklarına göre ortalama 253 bin ton/yıl üretimiyle İran birinci sırada yer alırken, bunu 149 bin ton/yıl ile A.B.D. izlemektedir. Türkiye 96 bin ton ile üçüncü sırada yer almaktadır (Anonymous, 2011).

Ekonomik öneme sahip meyveler olan armut ve antep fıstığı üretiminde birim alandan alınan ürün miktarının düşük olma sebeplerinden birisi hastalık ve zararlılardan kaynaklanmaktadır. Bunlar içinde gerek armudun gerekse antep fıstığının en önemli zararılıarı arasında yaprak pireleri olarak da bilinen yaprak psyllidleri (Hemiptera: Psyllidae) yer almaktadır (Er, 2008).

Yaprak ve sürgünlerde sokup emerek beslenen armut psyllidi armut ağaçlarında üç şekilde zarara sebep olmaktadır: Bunlardan ilki, Nimflerin beslenmeleri sırasında salgıladığı ballı madde ağaçların yaprak, dal, sürgün ve meyvelerini kaplayarak fumajine neden olmaktadır. Siyahlaşan meyvelerin pazar değeri de önemli ölçüde düşmektedir. İkinci olarak, zararlı beslenme sırasında yaprak dokusuna toksin salgılayarak yapraklarda 'psylla şoku' adı verilen siyah yanıklara neden olmaktadır ve belki de en önemlisi olan üçüncü zarar şekli 'Perry hastalığı' ve 'Armut göçüren' gibi bazı armut hastalık etmenlerini bir ağaçtan diğerine taşımasıdır (Anonymous, 1991; Davies et al., 1992; Carraro, 1998). Ayrıca armut psyllidleri ‘Pear decline' olarak bilinen önemli bir armut hastalığının etmeni olan mycoplasmayı da taşıdığı bilinmektedir (Önuçar, 1983; Winfield et al., 1984; Davies et al., 1992; Carraro, 1998). Bu hastalık armutta önemli verim kayıplarına neden olmakta ve yetiştiricilerimiz tarafından etkili mücadelesi yapılamamaktadır (Önuçar, 1983; Özkan, 1986).

Antepfıstığı psyllidi de armut psyllidine benzer zarara sahip olmasının yanında yaprakların, karagözlerin dökülmesine ve meyvelerin iç doldurmamasına neden olmaktadır ayrıca genç ağaçlarda zarar etkisini daha fazla göstermektedir (Anonymous, 2010).

Zararlılarla mücadelede üreticiler tarafından bilinçsiz ve yüksek dozlarda pestisit kullanımı çevre kirliliği ve insan sağlığı üzerindeki olumsuz etkileri gibi riskleri de beraberinde getirmesi gibi zararların bu pestisitlere dayanıklılık kazanması da söz konusu olmaktadır. Bu nedenlerden dolayı son yıllarda kimyasal ilaçların kullanımını azaltıcı alternatif yöntemler üzerinde araştırmalara hız verilmiştir (Coşkuncu, 2005).

$\mathrm{Bu}$ alternatifler arasında feromon tuzakların kullanımı ilk sıralarda yer almaktadır. Pestisit kullanımını engellemek ya da entegre mücadele programı çerçevesinde diğer mücadele yöntemleriyle kombine ederek ilaçlama sayısını en aza indirmek, kitle halinde tuzakla yakalama yönteminin amacını oluşturmaktadır (İnaç \& Laz, 2001).

Armut psyllidlerinin gözlemlenmesi için sarı yapışkan tuzakların kullanımı ilk kez Kaloostian \& Yeomans (1944) tarafından ortaya atılmıştır ve bu metot birçok araştırmacı tarafından kullanılmıştır (Kaloostian, 1961; Adams \& Los, 1989; Krysan \& Horton, 1991; Horton, 1993; Brown et al., 2009). 
Bu çalışma, söz konusu kitle halinde tuzakla yakalama yöntemine, katkıda bulunmak amacıyla, Türkiye'de ve dünyada armut ve antep fıstığının ana zararlıları arasında yer alan $C$. pyrii ve A. pistaciae yaprak psyllidlerine karşı Novagrica biological products and solutions (Fransa) firması tarafından üretilen, CacPyr Attractants for Psyllids isimli yeni bir feromon formülasyonu ve çeşitli tuzak kombinasyonlarının kullanılması suretiyle, 2014 yılı Mart - Temmuz ayları arasında Muğla ili Ula ilçesinde iki farklı armut üretim bahçesinde ve Şanlıurfa ili Suruç ilçesinde bir antepfıstığı üretim bahçesinde yürütülmüştür.

\section{Materyal ve Yöntem}

2014 Mart - Temmuz ayları arasında gerçekleştirilen çalışmanın ana materyalini Muğla İli Ula ilçesinde C. pyri ile yoğun bulaşık iki farklı armut bahçesi ve Şanlıurfa ili Suruç ilçesinde A. pistaciae ile yoğun bulaşık bir antepfıstığı bahçesi oluşturmuştur. Çalışmada yeni bir feromon formülasyonu deneme amaçlı kullanılmıştır.

\section{Arazi çalışmaları}

Muğla ili Ula ilçesinde denemeler Cacopsylla pyri ile yoğun bulaşık, 11 dekarlık 12 yaşında Santa Maria çeşidi armut yetiştirilen bir bahçede ve 12 dekarlık 12 yaşında Santa Maria cinsi armut yetiştirilen bir diğer bahçede olmak üzere iki farklı bahçede gerçekleştirilmiştir. Antep fıstığı denemeleri ise Agonoscena pistaceae ile yoğun bulaşık, Şanlıurfa ilinin Suruç ilçesinde 30 dekarlık 18 yaşında Tekin cinsi bir antepfıstığı bahçesinde gerçekleştirilmiştir.

Denemeler, armut ve antep fıstığı bahçelerinde üç karakterli (sarı yapışkan tuzak, sarı yapışkan tuzak+feromon kapsül, delta tuzak+feromon kapsül) ve 8 tekerrürlü olarak 15.03.2014 tarihinde kurulmuştur. Tuzaklar arası mesafe $15 \mathrm{~m}$ olarak alınmış olup tuzaklar yerden 1,5-2 m yükseklikte ve güney-doğu yönüne doğru asılmıştır. Sayımlar aylık olarak yapıımış olup dört ay sürmüştür. Tuzaklar ve dispenserler güneş ışığı ve diğer çevresel etkenler göz önünde bulundurularak feromonun etki süresine ve yapışkan tuzakların kirlenip deforme olma durumuna göre ayda bir olarak değiştirilmiştir. Güneş ve diğer çevresel etkenler tuzağın başarısını etkileyebilmektedir. Ancak sayım sonuçları incelendiğinde bu olumsuzluğa rağmen sarı yapışkan tuzaklar oldukça etkili bulunmuştur.

\section{Laboratuvar çalışmaları}

Tüm deneme bahçelerinde ayda bir kez yenileri ile değiştirilen sarı yapışkan tuzak, sarı yapışkan tuzak+feromon kapsül ve delta tuzak+feromon kapsül tuzakları $20 \times 30 \mathrm{~cm}$ ebatlarındaki fitilli geçmeli tuzak kutularında, birbirlerine değmeyecek şekilde sıralanarak, üzerlerindeki psyllid erginleri erkek ve dişi bireyler halinde sayılmıştır.

\section{Data analizi}

Elde edilen ergin değerlerine Tuzak Etkinliği (\%) formülü (Anonymous, 2011) uygulanarak tuzakların yüzde etkileri belirlenmiş, SPSS (15.0) Software paket programı kullanılarak tek yönlü Varyans analizi ve Duncan testi uygulanarak tuzaklar arasındaki etki farklılıkları saptanmıştır $(p=0,05)$

$$
\text { Tuzak etkinliği }(\%)=\frac{\mathbf{A}}{\mathbf{A}+\mathbf{B}} \times 100
$$

A: Deneme tuzağındaki toplam birey sayısı

B: Sarı yapışkan (Kontrol) tuzaktaki toplam birey sayısı 


\section{Araştırma Sonuçları ve Tartışma}

Muğla ili Ula ilçesinde armut bahçelerinde feromon+yapışkan renk tuzağı, delta tuzak+feromon preparatı kombinasyonlarında ve sadece sarı yapışkan tuzaklardaki $C$. pyri' nin laboratuvarda yapılan sayımlar sonucu elde edilen birey sayıları ve \% tuzak etkinliği Çizelge 1'de verilmiştir.

Çizelge 1. 2014 yılında Muğla ili Ula ilçesindeki iki farklı armut üretim bahçesinde denenen çeşitli tuzak kombinasyonlarında tuzaklarda sayılan Cacopsylla pyri' ye ait dişi-erkek birey sayıları ve \% tuzak etkinlikleri

\begin{tabular}{|c|c|c|c|c|c|c|c|c|c|c|c|c|c|}
\hline \multicolumn{2}{|l|}{ 1.Bahçe } & \multicolumn{3}{|c|}{15.04 .2014} & \multicolumn{3}{|c|}{15.05 .2014} & \multicolumn{3}{|c|}{15.06 .2014} & \multicolumn{3}{|c|}{15.07 .2014} \\
\hline $\begin{array}{c}\text { Tuzak } \\
\text { Kombinasyonları }\end{array}$ & $\begin{array}{l}\text { Tuzak } \\
\text { Adeti }\end{array}$ & Dişi & Erkek & $\begin{array}{c}\% \\
\text { Tuzak } \\
\text { Etkinliği }\end{array}$ & Dişi & Erkek & $\begin{array}{c}\% \\
\text { Tuzak } \\
\text { Etkinliği }\end{array}$ & Dişi & Erkek & $\begin{array}{c}\% \\
\text { Tuzak } \\
\text { Etkinliği }\end{array}$ & Dişi & Erkek & $\begin{array}{c}\% \\
\text { Tuzak } \\
\text { Etkinliği }\end{array}$ \\
\hline $\begin{array}{l}\text { Feromon+Sarı } \\
\text { YapışkanTuzak }\end{array}$ & 8 & 50 & 16 & 53.23 & 140 & 38 & 60.14 & 95 & 61 & 49.68 & 852 & 486 & 45.96 \\
\hline $\begin{array}{c}\text { Feromon+Delta } \\
\text { Tuzak }\end{array}$ & 8 & 3 & 2 & 7.94 & 9 & 4 & 9.92 & 2 & 0 & 1.25 & 53 & 29 & 4.95 \\
\hline $\begin{array}{c}\text { Sarı Yapışkan Tuzak } \\
\text { (Kontrol) }\end{array}$ & 8 & 37 & 21 & - & 75 & 43 & - & 110 & 48 & - & 949 & 624 & - \\
\hline 2.Bahçe & & & 15.04 .20 & & & 15.05 .20 & & & 15.06 .20 & & & 15.07 .20 & \\
\hline $\begin{array}{c}\text { Tuzak } \\
\text { Kombinasyonları }\end{array}$ & $\begin{array}{l}\text { Tuzak } \\
\text { Adeti }\end{array}$ & Dişi & Erkek & $\begin{array}{c}\% \\
\text { Tuzak } \\
\text { Etkinliği }\end{array}$ & Dişi & Erkek & $\begin{array}{c}\% \\
\text { Tuzak } \\
\text { Etkinliği }\end{array}$ & Dişi & Erkek & $\begin{array}{c}\% \\
\text { Tuzak } \\
\text { Etkinliği }\end{array}$ & Dişi & Erkek & $\begin{array}{c}\% \\
\text { Tuzak } \\
\text { Etkinliği }\end{array}$ \\
\hline $\begin{array}{l}\text { Feromon+Sarı } \\
\text { YapışkanTuzak }\end{array}$ & 8 & 36 & 25 & 46.92 & 19 & 8 & 41.54 & 22 & 12 & 47.22 & 96 & 46 & 37.17 \\
\hline $\begin{array}{c}\text { Feromon+Delta } \\
\text { Tuzak }\end{array}$ & 8 & 4 & 1 & 6.76 & 3 & 2 & 11.63 & 4 & 2 & 13.64 & 39 & 20 & 19.73 \\
\hline $\begin{array}{c}\text { Sarı Yapışkan Tuzak } \\
\text { (Kontrol) }\end{array}$ & 8 & 49 & 20 & - & 23 & 15 & - & 24 & 14 & - & 207 & 33 & - \\
\hline
\end{tabular}

Çizelge 1 incelendiğinde birinci bahçede en yüksek tuzak etkinliği feromon+sarı yapışkan tuzağın 15.05.2014 sayımlarında görülmektedir bununla beraber en düşük tuzak etkinliği ise feromon+delta tuzağın 15.06.2014 sayımlarında görülmektedir. Genel olarak feromon+sarı yapışkan tuzağın, feromon+delta tuzaktan çok daha yüksek tuzak etkinliğine sahip olduğu bariz bir şekilde görülmektedir. Ancak \% tuzak etkinliği \% 90 ve üzeri olmadığı için, tuzaklar etkili olarak görülmemiştir (Anonymous, 2011). İkinci bahçede ise en yüksek tuzak etkinliği feromon+sarı yapışkan tuzağın 15.06.2014 sayımlarında görülmüş olup en düşük tuzak etkinliği ise feromon+delta tuzağın 15.04.2014 sayımlarında görülmektedir. İkinci bahçede de birinci bahçedeki gibi feromon+sarı yapışkan tuzağın, feromon+delta tuzaktan çok daha yüksek tuzak etkinliğine sahip olduğu bariz bir şekilde görülmektedir. Ancak \% tuzak etkinliği \% 90 ve üzeri olmadığı için, tuzaklar etkili olarak görülmemiştir (Anonymous, 2011).

Şanlıurfa ili Suruç ilçesinde antep fıstığı bahçesinde feromon+yapışkan renk tuzağı, delta tuzak+feromon preparatı kombinasyonlarında ve sarı yapışkan tuzaklardaki Agonoscena pistaciae erginlerinin laboratuvarda yapılan sayımlar sonucu elde edilen birey sayıları ve \% tuzak etkinliği çizelge 2'de verilmiştir.

Çizelge 2. 2014 yılında Şanlıurfa ili Suruç ilçesindeki bir antep fıstığı bahçesinde denenen çeşitli tuzak kombinasyonlarında tuzaklarda sayılan Agonoscena pistaciae' ye ait dişi-erkek birey sayıları ve \% tuzak etkinlikleri

\begin{tabular}{|c|c|c|c|c|c|c|c|c|c|c|c|c|c|}
\hline & & \multicolumn{3}{|c|}{15.04 .2014} & \multicolumn{3}{|c|}{15.05 .2014} & \multicolumn{3}{|c|}{15.06 .2014} & \multicolumn{3}{|c|}{15.07 .2014} \\
\hline $\begin{array}{c}\text { Tuzak } \\
\text { Kombinasyonları }\end{array}$ & $\begin{array}{l}\text { Tuzak } \\
\text { Adeti }\end{array}$ & Dişi & Erkek & $\begin{array}{c}\% \\
\text { Tuzak } \\
\text { Etkinliği }\end{array}$ & Dişi & Erkek & $\begin{array}{c}\% \\
\text { Tuzak } \\
\text { Etkinliği }\end{array}$ & Dişi & Erkek & $\begin{array}{c}\% \\
\text { Tuzak } \\
\text { Etkinliği }\end{array}$ & Dişi & Erkek & $\begin{array}{c}\% \\
\text { Tuzak } \\
\text { Etkinliği }\end{array}$ \\
\hline $\begin{array}{l}\text { Feromon+Sarı } \\
\text { YapışkanTuzak }\end{array}$ & 8 & 96 & 50 & 35.01 & 380 & 213 & 47.40 & 1127 & 613 & 46.04 & 3410 & 1830 & 43.86 \\
\hline $\begin{array}{c}\text { Feromon+Delta } \\
\text { Tuzak }\end{array}$ & 8 & 42 & 29 & 20.76 & 55 & 22 & 10.48 & 63 & 23 & 4.05 & 67 & 32 & 1.45 \\
\hline $\begin{array}{c}\text { Sarı Yapışkan Tuzak } \\
\text { (Kontrol) }\end{array}$ & 8 & 170 & 101 & - & 453 & 205 & - & 1500 & 539 & - & 4704 & 2003 & - \\
\hline
\end{tabular}


Çizelge 2 incelendiğinde en yüksek tuzak etkinliği feromon+sarı yapışkan tuzağın 15.05.2014 sayımlarında görülmektedir bununla beraber en düşük tuzak etkinliği ise feromon+delta tuzağın 15.07.2014 sayımlarında görülmektedir. Genel olarak feromon+sarı yapışkan tuzağın, feromon+delta tuzaktan çok daha yüksek tuzak etkinliğine sahip olduğu bariz bir şekilde görülmektedir. Ancak \% tuzak etkinliği \% 90 ve üzeri olmadığı için, tuzaklar etkili olarak görülmemiştir (Anonymous, 2011).

Denemede karşılaştırma karakteri olarak boş tuzak kullanıldığından dolayı deneme süresince denenen tuzakta yakalanan birey sayısı her iki tuzakta yakalanan toplam birey sayısına bölünerek tuzak etkinliği (\%) bulunmuştur (Anonymous, 2011). Bulunan \% etki sonuçlarının istatistiksel analizi SPSS (15.0) Software paket programı kullanılarak ONE-WAY ANOVA testi ve $P=0,05$ ' e göre Duncan range testi kullanılarak yapılmıştır. Her üç bahçedeki deneme sonuçlarına uygulanan istatistiksel analiz sonuçları Çizelge 3-4' de verilmiştir.

Çizelge 3. Muğla ili Ula ilçesinde yapılan denemelerdeki sayım sonuçlarının etki ortalamaları $( \pm S E)$

\begin{tabular}{ccc}
\hline Tuzak kombinasyonları & \multicolumn{2}{c}{ Etki Ortalamaları } \\
\hline & 1. bahçe & 2. bahçe \\
Feromon+Sarı yapışkan tuzak & $51,12 \pm 12,93 \mathrm{bc}$ & $10,53 \pm 2,5 \mathrm{~b}$ \\
Delta+Feromon tuzak & $6,56 \pm 1,76 \mathrm{a}$ & $3,56 \pm 0,92 \mathrm{a}$ \\
Sarı yapışkan tuzak & $59,28 \pm 15,30 \mathrm{c}$ & $8,93 \pm 1,71 \mathrm{~b}$ \\
\hline
\end{tabular}

*Aynı harfe sahip olan karakterler arasında Duncan range testine göre istatistiksel olarak fark yoktur $(P>0,05)$.

Çizelge 3' de görüldüğü gibi birinci deneme alanında denemeye alınan tuzak kombinasyonlarının etki sonuçlarının istatistiksel analiz sonuçlarına göre; tek başına sarı yapışan tuzak karakterinin diğer kombinasyonlara göre en yüksek bireyi yakaladığı ve istatistiksel olarak da farklı önemde olduğu saptanmıştır $(P<0,05)$. Bunu feromon+sarı yapışkan tuzak kombinasyonu izlemiş ve bu kombinasyon da delta+feromon tuzak kombinasyonundan farklı önemde saptanmıştır $(P<0,05)$.

İkinci deneme alanındaki istatistiksel analiz sonuçlarına bakıldığında; feromon+sarı yapışkan tuzak kombinasyonu ile sarı yapışkan tuzak karşılaştırıldığında bu iki tuzak kombinasyonunun en yüksek bireyi yakaladığı ve istatistiksel açıdan aralarında önemli bir fark olmadığı saptanmıştır $(P>0,05)$. Ancak bu iki tuzak kombinasyonu delta+feromon tuzak kombinasyonuyla karşılaştırıldığında istatistiksel açıdan farklı bulunmuştur $(P<0,05)$.

Yani her iki analiz sonucu delta tuzak+feromon kombinasyonunun diğer iki tuzak kombinasyonuna göre daha etkisiz olduğuna işaret etmektedir.

Çizelge 4. Şanlıurfa ili Suruç ilçesinde yapılan denemedeki sayım sonuçlarının etki ortalamaları $( \pm S E)$

\begin{tabular}{cc}
\hline Tuzak kombinasyonları & Etki Ortalamaları \\
\hline Feromon+Sarı yapışkan tuzak & $241,21 \pm 59,37 \mathrm{~b}$ \\
Delta+Feromon tuzak & $10,40 \pm 0,79 \mathrm{a}$ \\
Sarı yapışkan tuzak & $301,40 \pm 67,18 \mathrm{bc}$ \\
\hline
\end{tabular}

*Aynı harfe sahip olan karakterler arasında Duncan range testine göre istatistiksel olarak fark yoktur $(P>0,05)$.

Şanlıurfa ili Suruç ilçesinde $A$. pistaciae ile yoğun bulaşık deneme alanının istatistiksel etki sonuçları incelendiğinde ise yine armut denemesinin sonuçlarıyla çok benzer sonuçlar elde edilmiştir. Bu sonuçlara göre; tek başına sarı yapışkan tuzak karakterinin diğer kombinasyonlara göre en yüksek bireyi yakaladığı ve istatistiksel olarak da farklı önemde olduğu saptanmıştır $(P<0,05)$. Bunu feromon+sarı yapışkan tuzak kombinasyonu izlemiş ve bu kombinasyon da daha yüksek yakalama yüzdesiyle delta+feromon tuzak kombinasyonundan farklı önemde saptanmıştır $(P<0,05)$.

Yürütülen çalışmanın sonuçlarına göre armut ve antepfıstığının ana zararlıları konumundaki C. pyri ve $A$. pistaciae mücadelesinde sarı yapışan tuzakların tek başına veya feromon kapsül ile kombine 
olarak uygulandığında en etkili olduğu saptanmıştır. Ancak sarı yapışkan tuzak uygulamasının tek başına olan etkisi ile feromon kapsül ile kombine halde uygulandığındaki etkisi arasında istatistiksel olarak önemli bir fark görülmemiştir. Buna karşılık, C. pyri ve $A$. pistaciae mücadelesinde uygulanan delta tuzak+feromon kapsül kombinasyonunu ile sarı yapışkan tuzak+feromon kapsül kombinasyonu arasındaki fark istatistiksel olarak önemli bulunmuştur. Bu kombinasyonlardan elde edilen sonuçlar da bize feromon kapsüllerin delta tuzak ile kombine edildiğinde sarı yapışkan tuzaklar kadar cezbedici bir etkiye sahip olmadığını göstermektedir. Üç farklı bahçede yürütülen bu çalışmanın sonuçları birbirini doğrular derecesinde benzer çıkmıştır.

Yapılan literatür taramasında da çalışmanın sonuçlarını destekler nitelikte sarı yapışkan tuzakların psyllid erginlerini yakalama üzerinde oldukça etkili olduklarına dair pek çok çalışmaya rastlanmıştır.

Bugün bütün dünyada kullanılan feromon çalışmaları Türkiye'de birçok böcek türü için başarılı bir şekilde kullanılmaktadır (İnaç \& Laz, 2001). Bunun yanında sarı yapışkan tuzaklar da pek çok zararlıyla savaşta yaygın olarak kullanılmaktadır. Günümüze kadar yapışkan renk tuzaklarıyla ilgili pek çok çalışma gerçekleştirilmiştir (Durmuşoğlu et al., 2009). Seyedoleslami et al. (2003) İran' da yaptıkları çalışmada sarı yapışkan tuzakların $A$. pistaciae erginlerini yakalamada oldukça etkili olduklarını bildirmektedirler. Fazali et al. (2012) İran' da yaptıkları çalışmada A. pistaciae ergin populasyonunu farklı coğrafik bölgelerde bulunan fıstık ağacı (Pistacia vera L.) yetiştirme alanında sarı yapışkan tuzak kullanarak gözlemlemiştir. Ağaç başına 5 adet sarı yapışkan tuzak asmışlardır ve 2 hafta boyunca tuzaklarda yakalanan psyllid erginlerini saymışlardır. Sonuç olarak sarı yapışkan tuzakların A. pistaciae erginlerini yakalamada oldukça etkili olduklarını bildirmektedirler. Faezeh et al. (2010) İran' da yaptıkları çalışmada fıstık psyllidlerinin populasyon yoğunluklarının bölgelere göre değişiklik gösterip göstermediğini sarı yapışkan tuzaklar asarak Nisan ve Ekim ayları arasında periyodik sayımlar yaparak gözlemlemişlerdir. Sonuç olarak sarı yapışkan tuzakların $A$. pistaciae erginlerini yakalamada oldukça etkili olduklarını bildirmektedirler.

Gerek yapılan literatür taramaları gerekse de çalışmanın sonuçları incelendiğinde biyoteknik yöntemler içerisinde başarılı bir şekilde kullanılan yapışkan renk tuzaklarından sarı yapışan renk tuzağının Cacopsylla pyri ve Agonoscena pistaciae türlerine karşı oldukça etkili olduğu ve pratikte de kullanılabileceği açıkça görülmektedir. Ancak bu çalışmada denenen yeni feromon preparatı, Novagrica biological Products and Solutions (Fransa) firması tarafından üretilen, CacPyr Attractants for Psyllide isimli preparatın Cacopsylla pyri ve Agonoscena pistaciae için ümitvar bir etkiye sahip olmadığı bu çalışmanın sonuçları itibarıyla ortaya konulmuştur.

\section{Yararlanılan Kaynaklar}

Adams, R.G. \& L.M., Los, 1989. Use of sticky traps and limb jarring to aid in management decisions for summer populations of the pear psylla (Homoptera: Psyllidae) in Connecticut. Journal of Economic Entomology, 82: 1448-1454.

Anonymous, 1991. Integrated Pest Management for Apples and Pears. University of California, Division of Agriculture and Natural Resources, Pub. No: 3340, Oakland, CA, USA. p 314.

Anonymous, 2010. Tarım ve Köyişleri Bakanlığı Koruma ve Kontrol Genel Müdürlüğü. Antepfıstığı Hastalık ve Zararlıları ile Mücadele. (Web sayfası: http://www.tagem.gov.tr) (Erişim Tarihi: Eylül 2014).

Anonymous, 2011. Tarım ve Hayvancılık Bakanlığı Tarımsal Araştırmalar ve Politikalar Genel Müdürlüğü. Bitki Zararlıları Standart ilaç Deneme Metotları. Meyve ve Bağ Alanlarında Eşeysel Çekici ve Cezbedici Tuzaklar Standart Deneme Metodu. (Web sayfası: http://www.tagem.gov.tr) (Erişim Tarihi: Eylül 2014).

Anonymous, 2013. Türkiye İstatistik Kurumu. Ankara. (Web sayfası: http://tuikapp.tuik.gov.tr/bitkiselapp/bitkisel.zul) (Erişim Tarihi: Eylül 2014).

Brown, R.L., P.J. Landolt, D.R. Horton \& R.S. Zack, 2009. Attraction of Cacopsylla pyricola (Hemiptera: Psyllidae) to female Psylla in pear orchards. Environmental Entomology, 38: 815-822. 
Carraro, L., 1998. Transmission of pear decline by using naturally infected Cacopsylla pyri. Acta Horticulturae, 472 : 665-668.

Coşkuncu, K.S., 2005. Depolanmış ürünlerde zararlı böceklerle mücadelede feromon tuzakların kullanım olanakları. Ondokuz Mayıs Üniversitesi Ziraat Fakültesi Dergisi, 20 (2): 92-97.

Davies, D.L., C.M. Guise, M.F. Clark \& A.N. Adams, 1992. Parry's disease of pears is similar to pear decline and is associated with mycopiasma-like organisms transmitted by Cacopsylla pyricola. Plant Pathology, 41 (2): 195203.

Durmuşoğlu, E., M. Salaman, H.S. Civelek, A. Hatipoğlu \& H. Balcı, 2009. Effect of various hues of yellow as sticky trap color on leafminers in Cucumber growing greenhouses. Türkiye Entomoloji Dergisi, 33 (3): 163-170.

Er, Ş. H., 2008. Armut Zararlısı Cacopsylla pyri (L.) (Homoptera: Psyllidae)' nin Ankara İlindeki Biyolojisi Üzerinde Araştırmalar. Ankara Üniversitesi Fen Bilimleri Enstitüsü Bitki Koruma Ana Bilim Dalı (Basılmamış) Doktora Tezi, Ankara, 99 ss.

Faezeh, N., M.R. Mehrnejad \& M. Fallahzadeh, 2010. Population dynamics and density of the common Pistachio psylla, Agonoscena pistaciae (Hemiptera: Psyllidae) on two Pistachio cultivars, badami-riz zarand and momtaz. Plant Protection Journal, 2 (3): 209- 222.

Fazeli, S.A., G.H. Davarynejad \& H. Sadeghi, 2012. Influence of geographıcal directıon and Pistachio cultivar on the capture of adult Pistachio psylla by Yellow stıcky card. ISHS Acta Horticulturae. 933: 523-527.

Horton, D.R., 1993. Diurnal patterns in yellow trap catch of Pear psylla (Homoptera: Psyllidae): differences between sexes and morphotypes. Canadian Entomology, 125: 761-767.

İnaç, S. \& B. Laz, 2001. Kahramanmaraş andırın kızılçam ormanlarında zarar yapan büyük orman bahçıvanı (Blastophagus piniperda Lin.)' na karşı feromon denemesi ve sonuçları. Fen ve Mühendislik Dergisi, 4(2): 7380.

Kaloostian, G.H., 1961. Evaluation of adhesives for sticky board traps. Journal of Economic Entomology, 54: 10091011.

Kaloostian, G. H. \& M. S. Yeomans, 1944. A Sticky Board Trap Used in Scouting for Pear Psylla. U.S. Bur. Entomol. Plant Quar. ET-220, p 6.

Krysan, J.L. \& D.R. Horton, 1991. Seasonality of catch of Pear psylla Cacopsylla pyricola (Homoptera: Psyllidae) on yellow traps. Environmental Entomology, 20: 626-634.

Önuçar, A., 1983. İzmir ve Çevresindeki Bitkilerde Zararlı Psyllid (Hom: Psyllinea) Türlerinin Tanınmalan, Konukçuları ve Taksonomileri Üzerinde Araştırmalar. T.C. Tarım ve Orman Bakanlığı, İzmir Bölge Zirai Mücaldele Araştırma Enstitüsü Müdürlüğü, Araştırma Eserleri Serisi. No:44 Ankara. $122 \mathrm{~s}$.

Özkan, A., 1986. Antalya İlinde Yumuşak Çekirdekli Meyve Ağaçlarının Coleoptera ve Heteroptera Takımlarına Ait Faydalı Böcek Türleri, Tanınmaları, Konukçuları ve Önemlilerinin Etkinlikleri Üzerinde Araştırmalar. Antalya Biyolojik Mücadele Araştırma Eserleri serisi No.5, 1 - 80.

Seyedoleslami, H., A.R. Hadian \& A. Rezai, 2003. Estimation of population density of first and second instar nymphs of pistachio psylla, Agonoscena pistaciae (Hom: Psyllidae) from adult Psylla capture on yellow sticky traps. JWSS - Isfahan University of Technology, 1: 223-232.

Soylu, A., 1997. Ilıman İklim Meyveleri-2, Uludağ Üniversitesi Ders Notları No: 72, Bursa, 245 s.

Winfield, A.L., M. Hancock, A.W. Jackson \& R.P. Hommon, 1984. Pear succer P. pyricola in Southeast England Srop/Wprs Bull, 7 (5): 45-54. 